\title{
La comunicación política como instrumento conformador de valores y actitudes. Evolución y estado de la cuestión
}

Political communication as an instrument to conform values and attitudes. Evolution and state of the question 
RESUMEN

Clasificación JEL:

M37, M38

Palabras clave:

Propaganda,

Publicidad Política,

Publicidad Electoral,

Publicidad Comer-

cial, Comunicación

Política, Marketing

Político

ABSTRACT

\section{JEL Classification: \\ M37, M38 \\ Key words:}

Propaganda, Political

Advertising, Election

Advertising, Com-

mercial Advertising,

Political Commu-

nication, Political

Marketing.
El desarrollo conceptual y estratégico de la comunicación política como un elemento cada vez más importante en el posicionamiento estratégico de los partidos políticos y las instituciones públicas, con el soporte fundamental de los medios de comunicación tradicionales - prensa, radio y televisión-, y los cambios producidos en el modelo clásico tras la irrupción y paulatino asentamiento de las Nuevas Tecnologías -Internet y las redes sociales-, son el punto de partida de este artículo.

El objetivo del mismo descansa en la necesidad de ahondar en la evolución y desarrollo de estas estrategias - de la transmisión de ideología a la permeabilización en ellas de técnicas propias del mercado-, acercándonos a esta parcela de la comunicación con un espíritu crítico, desde una perspectiva analítica que nos permita llegar a una síntesis interpretativa del fenómeno. Para ello obtendremos los datos de primera mano que nos acerquen al conocimiento de su evolución, desarrollo y actual situación. El marco teórico que se obtendrá de este estudio servirá como base a posteriores líneas de investigación.

El estudio se aborda desde la interpretación de las distintas fuentes originales, que nos permiten investigar las distintas variables en juego. El procedimiento para discriminar las fuentes utilizadas será el muestreo de juicio, primando los autores e instituciones de reconocido prestigio nacional e internacional.

The conceptual and strategic development of political communication as an ever more important element in the strategic positioning of political parties and public institutions, with the fundamental aid of the traditional means of communication -press, radio and television-, and the changes that have occurred in the classical model as a result of the impact and increasing acceptance of the New Technologies-internet and the social networks, are the starting point in this article.

Its objective lies in the need for an in-depth study of the evolution and development of these strategies -from the broadcasting of ideology to the permeation of marketing techniques in them-, bringing us closer to this section of communications with a critical spirit, from an analytical perspective that allows us reach an interpretative synthesis of the phenomenon. In order to do this we will obtain first hand data that bring us closer to learning about its evolution, development and current situation. The theoretical model obtained from this study will serve as the basis for future lines of research. 


\section{Introducción}

A la hora de afrontar hoy el fenómeno de la comunicación política sólo hay una evidencia segura: la importancia creciente de la misma. Y nos bastaría con hojear los diarios para entresacar algunas noticias recientes a partir de las cuáles observamos este axioma con mayor claridad. La última remodelación del Gobierno de España obedece casi exclusivamente a criterios de comunicación ${ }^{1}$ (El País, 2010), el primero de los contratiempos del reciente primer ministro británico tiene como causa la salida de su jefe de comunicación² (Openheimer, 2011), la Convención Nacional del PP español como gran evento de comunicación sin contenidos ${ }^{3}$ (El Mundo, 2011) o las campañas de publicidad (hasta ocho paralelas) lanzadas por la Presidenta de la Comunidad de Madrid para activar la comunicación en período pre-electoral ${ }^{4}$. Todas arrojan luz sobre el fenómeno.

La comunicación política no sólo se ha desideologizado y ha comenzado a utilizar las mismas técnicas que el marketing de productos; la comunicación política no sólo obedece cada vez más a una retórica performativa -los discursos son los que fabrican las realidades- que ya no tiene por objeto transmitir información, ideas ni aclarar decisiones, sino actuar sobre las emociones y los estados de ánimo de los electores -que

1 "Zapatero ha señalado que acomete la renovación con el objetivo de fortalecer el discurso político del Gobierno y de explicarse mejor".

2 "David Cameron sufrió ayer su primer descalabro político de calado desde que llegó a Downing Street con la dimisión de su ideólogo mediático y director de Comunicación del Gobierno".

3 "...para que su plan no se quede sólo en el reclamo de una gran operación de marketing, a esta música ... el PP deberá ponerle ahora la letra".

4 "El gobierno de Esperanza Aguirre ha activado el proceso para lanzar ocho campañas de publicidad justo antes de los comicios de mayo". cada vez son más el público de un espectáculo(Salmon, 2007, p. 153); no sólo se ha desplazado a lo largo de los diferentes medios de comunicación, desde la prensa escrita, pasando por la TV hasta instalarse en los diferentes fenómenos de Internet -ahora las redes sociales- sin terminar de salir de ninguno; sino, lo que es más importante, ha desbordado su espacio específico y restringido: las convocatorias electorales, pasando a ocupar un espacio creciente y continuado en el tiempo, de modo que podríamos decir que en los últimos veinte años la vida democrática ha dado un giro hacia una campaña electoral permanente e ininterrumpida dominada por las nuevas tecnologías, lo que permite penetrar en la opinión pública en tiempo real. La mayoría silenciosa.

De ahí la idea de adentrarnos en profundizar en el conocimiento de esta materia hasta llegar a su situación actual, para lo que obtendremos informaciones de primera mano que nos acerquen a su conocimiento. Así, nos adaptaremos metodológicamente a las fuentes documentales que nos proporcionarán los parámetros para dilucidar el estado de la cuestión.

Y todo ello nos llevará a las conclusiones que se derivarán de ésta investigación, y sus futuras consecuencias.

\section{Objetivos y metodología}

El objetivo principal de esta investigación se fundamenta en la necesidad de ahondar en la evolución, desarrollo y actual situación de la Comunicación Política, acercándonos a esta parcela de la comunicación con un espíritu crítico, desde una perspectiva analítica que nos permita llegar a una síntesis interpretativa del fenómeno para obtener un estado de la cuestión. 
Como objetivo subsidiario obtendremos un conocimiento actualizado, y de primera mano del fenómeno, que nos permitirá abrir nuevas líneas de investigación.

El método utilizado para la selección de las distintas fuentes en las que se asienta la investigación es el juicio personal de los investigadores como expertos en la materia en la medida dada. La ventaja que tiene este método es la facilidad de acceso a una muestra amplia, y por tanto representativa y sustantiva.

\section{Estado de la cuestión. Situación actual}

\section{Conceptos: terminología}

No hay una definición única, a pesar de que tampoco los estudios son profusos en definiciones, ya que la tendencia es a describir técnicas y casos concretos a pesar de la abundante literatura sobre el tema.

Explicar la terminología que define y hace comprensible esta materia, la Comunicación Política, y de otras materias colindantes, es fundamental. Al ser un término en constante evolución, y haberse usado de modo muy ambiguo, es necesario aclarar cuáles son las distintas formas en que se ha denominado éste fenómeno a lo largo del tiempo y así llegar al estado actual del término.

Empecemos por Propaganda, un término que ha definido tanto un sistema de desarrollo y extensión de afirmaciones falsas, mentiras dirigidas a la transformación completa de las mentes, juicios, valores y acciones constituyendo un marco de referencia para la falsificación sistemática (Ellul, 1965, p. 61), como la propagación de las ideas mediante las cuales una determinada opción política trata de ofrecer a los ciudadanos una visión de la sociedad distinta a la de sus concurrentes (Caro, 2008, p. 9). En este segundo sentido, se ha producido una erosión del término que ha llevado a utilizar como sinónimo de Propaganda el de Publicidad Política -sin apenas signos de diferenciacióncomo actividad comunicativa a través de la cual un individuo o grupo de individuos se sirven para difundir sus ideas y neutralizar las opuestas, todo ello con el fin último de alcanzar el poder o, en caso de poseerlo, de mantenerse en él (Huici, 1994, p.97). Se podría confundir con la Publicidad Comercial a pesar de que la Ley General de Publicidad de 11 de noviembre de 1988 -Artículo $2^{\circ}$, Apartado $1^{\circ}$-, señala el inequívoco carácter comercial: Toda forma de comunicación realizada por una persona física o jurídica, pública o privada, en el ejercicio de una actividad comercial, industrial, artesanal o profesional, con el fin de promover de forma directa o indirecta la contratación de bienes muebles o inmuebles, servicios y obligaciones. Y también se utiliza como sinónimo la Comunicación Política -título de nuestro artículo- que podemos definir (en su acepción primigenia) como uno de los tres procesos (junto con el liderazgo político y las estructuras del grupo) de intervención por medio del cual se movilizan y transmiten las influencias políticas entre unas instituciones gubernamentales y el ciudadano votante (Nimmo y Sanders, 1981, p. 50).

Otro término también se confunde, es el de Marketing Político, que para Benito -que lo tiene claro hace décadas- es el uso programado de las diversas técnicas de comunicación, publicidad y relaciones públicas, dirigido a conseguir adhesiones para personas y programas políticos, sirviendo para el mantenimiento de la imagen de quien está, o quiere estar, en el poder, y también para destruir la imagen del adversario ante la opinión pública (Benito, 1976, p.12).

Otros dos términos relativamente recientes que también pueden crear dudas son el de Co- 
municación Institucional y Publicidad Institucional. Por el primero, Comunicación Institucional, se entiende aquella que se realiza de modo organizado por una institución y dirigida a las personas y grupos del entorno social donde realiza su actividad; su objetivo es establecer relaciones de calidad entre la institución y los públicos a los que se dirige, dándose a conocer socialmente y proyectando una imagen pública adecuada a sus fines y actividades. Por el segundo, Publicidad Institucional, se entiende como un elemento más de la comunicación pública que sirve a los poderes públicos para intercambiar y compartir información de utilidad con los ciudadanos (ANEI, 2011, p.1).

Y por último, el término que está muy bien diferenciado del resto pero que conviene aclarar por estar bastante próximas sus actividades, es el de Relaciones Públicas como la disciplina encargada de gestionar la comunicación entre una organización y un mapa de públicos clave para construir, administrar y mantener su imagen positiva.

\section{Evolución}

\section{- De la propaganda a la publicidad política}

Podríamos remitirnos a los precedentes lejanos de la comunicación política como hace Del Rey yéndonos a la Grecia Antigua (Del Rey, 1989, p. 78), dónde los sofistas eran los maestros del saber en una época de crisis cultural y grandes cambios que suponía el paso del período cosmológico al período antropológico y dónde imponían sus falsos argumentos manipuladores. O también nos podríamos remitir a los romanos que, como curiosidad, fueron autores del primer manual del candidato, escrito por el hermano de Cicerón en el 65 a. C. (Canel, 2005, p.12). Pero no debemos mirar tan atrás sino a tiempos mucho más cercanos que permitieron el nacimiento de un instrumento de propagación de mensajes de contenidos ideológicos diversos que se le denominó propaganda.

En las primeras décadas del siglo XX una serie de crisis consecuencia de la I Guerra Mundial, del rechazo a la revolución social y la revolución conservadora ayudaron a la instauración en Europa de regímenes políticos totalitarios de signo fascista: Italia, España, Portugal o Alemania, y la Revolución rusa el régimen soviético. Según Huici, hubiese sido muy difícil que hubieran llegado o se hubieran sostenido en el poder tanto Mussolini como Stalin y, sobre todo, Hitler sin la maquinaria propagandística de sus regímenes (Huici, 1993, p.98). Los receptores, en ésta primera mitad del siglo XX, aumentan en número de modo que el público del que se trata no está limitado en absoluto al cuerpo electoral de una nación: más bien se trata de todos los que son capaces de percibir y comprender los mensajes difundidos en el mundo (Ferry, Wolton et al. 1995, p.19).

En el desarrollo de la propaganda (que va parejo a un desarrollo social, político y económico) se pueden distinguir tres grandes etapas:

a. Propaganda elitista: corresponde a un período en el cual los únicos instrumentos de comunicación eran la palabra escrita y el discurso, y está orientada a una élite.

b. Proselitismo político y agitación de masas: el desarrollo político y social que experimentan muchos países desde fines del siglo pasado y comienzos de éste, tiene su correlato en una segunda etapa de la propaganda política, caracterizada entre otros elementos, por el surgimiento de grandes utopías. A la utopía anarquista sigue la del socialismo en sus diferentes vertientes, 
desde el socialismo utópico al socialismo marxista (Castillo, 1988, p. 42).

c. Publicidad política: el contexto sociológico, político y económico sufre un evidente cambio a partir de la década del sesenta y más drásticamente a contar de los setenta. Poco a poco, el concepto de agitación y propaganda, todavía en boga hasta fines de los años 60, deja paso al concepto de publicidad política, cuya definición básica consiste en la difusión de doctrinas, imágenes y programas políticos no ya con fines proselitistas o de captación de militantes, sino más bien con fines de ganar electores o simpatizantes a tal o cual partido y candidato (Castillo, 1988, p.44-45). Así se puede decir que la publicidad política sustituye, después de la Segunda Guerra Mundial, al vocablo propaganda.

Conviene recordar que en algunos países latinoamericanos se sigue utilizando la palabra propaganda como sinónimo de comunicación política, e incluso como sinónimo de publicidad. En cambio, en los países europeos es una palabra estigmatizada por su carga peyorativa, que no debe mezclarse ni confundirse con los términos publicidad comercial, publicidad política o comunicación política (Huici, 1993, p. 98). En este sentido ilumina la aclaración conceptual de Antonio Pineda para quien, según su criterio, bajo el término publicidad se entiende la publicidad comercial, considerando que el carácter comercial de esta actividad de comunicación es conceptual e históricamente determinante en ella, mientras la publicidad política es una extrapolación de los procedimientos y los formatos mediáticos de la publicidad comercial al ámbito mediático (Pineda, 2007, p. 108). Alfonso Méndiz matiza constatando la reciente confluencia entre los ámbitos comercial y propagandístico en términos publicitarios -el fenómeno publicitario se habría expandido al ámbito de las ideasy diferenciando entre publicidad política-subgénero de la publicidad social que integraría todas las campañas de los procesos electorales que informan de los propios proyectos sociales y racionalizan la actividad ciudadana en los comiciosy propaganda -que incluiría las campañas políticas destinadas a deformar la realidad o a denigrar al contrario- (Méndiz, 2007, 59).

\section{- De la publicidad política (marke- ting electoral) a la comunicación política (marketing político)}

La publicidad política es la herramienta que permite a los candidatos comunicar a los electores su superioridad sobre sus oponentes. Este mensaje se dirige a los electores escogido como blanco con base en una investigación previa y se caracteriza porque está controlado en todos sus aspectos para influir su voto y porque se transmite por medios masivos. (Diccionario, 2004). Así podemos decir que en el marketing electoral el objetivo es concreto: ganar unas elecciones del tipo que sean (Barranco, 2010, p.13).

Es obvio que los que saben comunicación social no son precisamente aquellos a los que está destinada la comunicación, esto es, los receptores de los mensajes de la política. Los que saben comunicación están en las grandes firmas publicitarias y en los gabinetes de marketing, al servicio de candidatos y partidos políticos (Del Rey, 1989 , p. 76). Este es el gran salto cualitativo que nos lleva al siguiente paso, la comunicación política, la entrada de los expertos y la consiguiente aplicación de las estrategias de comunicación y marketing. 
La comunicación política (marketing político), además de compartir con el marketing electoral el objetivo inicial de ganar elecciones, va más allá, en el sentido de que se constituye en el instrumento que permite establecer las bases para seguir ganando elecciones o, con palabras de marketing, para convencer a los votantes a través del convencimiento de la eficacia y eficiencia del partido, sindicato o cualquier otro tipo de organización democrática durante el período de gobierno o postelectoral (Barranco, 2010, p.13). Se puede concluir en definitiva que la Comunicación Política (con mayúsculas) es un expresión que designa un campo de reciente y creciente desarrollo en el entorno académico científico y, la misma autora, sigue diciendo que la comunicación política (con minúscula) es un término amplio, apenas utilizado en el mundo profesional, que incluye una serie de fenómenos comunicativos como la propaganda, el marketing electoral, el marketing político, las relaciones públicas o la comunicación institucional política (Canel, M.J., 2005, p.15).

\section{- De la comunicación política (mar- keting político) a la comunicación política 2.0}

Desde un punto de vista estratégico estamos asistiendo a una transformación del marketing en general y, como no podía ser menos, de su especialidad política en particular, debido a la irrupción de la Nuevas Tecnologías (Barroso, 2010, p.149) que se concretan hoy en las redes sociales y la web 2.0; Nuevas Tecnologías que han producido un gran impacto en los procesos informativos y comunicativos que influyen de forma determinante en la comunicación política y que han dado forma a lo que hoy denominamos comunicación política 2.0.
Esta no nos indicará quién votará a quién, pero sí permitirá hacer un seguimiento personalizado de los potenciales votantes, saber quiénes están participando activamente en la campaña o crear comunidades de activistas que trabajen a favor de la organización (Barroso, 2010, p.150), como ya hemos visto en la última campaña electoral norteamericana.

\section{Elecciones, campañas y candidatos}

Dejando de lado a Cicerón y a Maquiavelo como padres ideales de la comunicación política, definitivamente el marketing político es producto de la segunda mitad del siglo XX y se empezó a aplicar ya plenamente -sustituyendo a las otras formas de comunicación política- en las campañas electorales de los años cincuenta en EEUU para no dejar de crecer. Podemos pensar que las campañas tenían ya antes componentes del marketing y que la sofisticación que se suma en los últimos años es la que lleva a tener en cuenta al marketing electoral como materia independiente. También podemos considerar el marketing político como una mera aplicación de la teoría y las técnicas del marketing comercial a la política en sustitución de la mera comunicación de las ideas políticas. (Martín, 2002, p. 45).

Independientemente de la zozobra ética suscitada -en el fondo no debería sorprendernos que políticos y publicitarios se descubrieran mutuamente- se trata del comienzo de una era nueva. Desde el I like Ike de Eisenhower hasta el Yes we can de Obama pasando por La force tranquille de Séguèla para Mitterrand o el Zetapé de Rodríguez Zapatero, asistimos al vaciado ideológico de las campañas electorales y a la presentación de los partidos como si fueran simples empresas de servicios con capacidad para la gestión de un país. 
Con alguna excepción previa e intuitiva en el uso de la técnica publicitaria en la comunicación política -como es el caso del candidato a la presidencia William Henry Harrison en 1840, que se presentó ante el electorado como un granjero criado en los bosques y utilizó el símbolo de una choza identificándose con los votantes rurales, aunque en realidad pertenecía a la burguesía, era hijo de un gobernador y poseía una mansión en Georgia. Ganó las elecciones (Jamieson, 1996, p. 9)-. La necesaria sintonía entre políticos y publicitarios vino de la mano de las dos guerras mundiales y las inmensas campañas de propaganda que se realizaron para concienciar a la población de los problemas derivados de las mismas. Al terminar la II Guerra Mundial las técnicas de propaganda habían demostrado prácticamente todo su potencial. El papel de la radio había sido fundamental -por ejemplo en la colocación de bonos de guerra en maratones de radio (Schramm, 1965, p. 311)-, pero un nuevo medio, la televisión, dará el paso definitivo convirtiéndose en la herramienta a través de la cual llegar a los ciudadanos. Sus alumnos más aventajados en el aprendizaje de su capacidad de persuasión fueron los publicitarios, de modo que resultó inevitable que la política deviniera en un nuevo objeto del discurso de la publicidad (Eguizábal. 1998, p. 357).

La comunicación política profesional había nacido ya en California para las elecciones de 1933 gracias a Campaign Inc., puesta en marcha por Clem Whitaker y Leone Baxter (Mori, 2010, p. 66). Y las cuñas de radio en política se habían utilizado ya en 1936 para complementar los mítines en aquellas regiones donde los discursos del candidato tuvieran lugar en horas de poca audiencia.
Pero la idea de emplear una parte importante del presupuesto de la campaña en cuñas y spots publicitarios protagonizados por el propio candidato como presentador de su causa la sugiere en 1948 E. H. Little-presidente de Colgate-Palmolive-, quien encargó a la agencia Ted Bates la preparación de cuñas de radio para la campaña de Thomas E. Dewey. Éste rechazó la idea (Eguizábal, 1998, p. 360).

\section{- 1952. Un presupuesto para la comunicación política}

La campaña electoral de 1952 será la primera ocasión en que los partidos dediquen la mayor parte de sus presupuestos específicamente a la comunicación política. Y el momento en que todo cambie definitivamente: aparece en campaña la televisión y aparecen los primeros spots políticos realizados expresamente para el medio, que se convierte en la herramienta electoral decisiva. También se inaugura el marketing directo por correo y las encuestas de opinión para decidir qué temas se discuten en campaña.

Rosser Reeves orquestó un verdadero plan de campaña para el candidato republicano Dwight Ike Eisenhower que preconizaba el empleo de radio y televisión rompiendo momentáneamente las emisiones durante los últimos diez días de la campaña con instantáneas publicitarias para estimular a los electores a ir a las urnas y votar al candidato (Mayer, 1965, p. 493). De aquí en adelante la publicidad se introdujo en la política y se desterró cualquier susceptibilidad al empleo de cuñas o spots. La política comunicativa de los republicanos les dio una ventaja que los demócratas no contrarrestarían hasta la llegada de Kennedy, un presidente a medida para la televisión. 
Los spots ${ }^{5}$-hasta cincuenta con una duración de 30 segundos- modificaron la percepción del candidato suavizando su aureola de héroe de guerra haciéndolo cercano al electorado; se revisaron todos los discursos de Ike consagrando apenas una docena de temas generales tras consultar con George Gallup (a través del American Institute of Public Opinion mediante sondeos de opinión de la masa social) las principales preocupaciones de los ciudadanos americanos; además, montó encuentros ficticios en los que primero se rodaba al público formulando una pregunta al candidato, como si éste estuviera presente y, días después, a Ike respondiendo adecuadamente. El montaje hizo el resto (Eguizábal, 1998, p. 358-359). Todo atado con el lazo de un eslogan: I like Ike.

Reeves explicaba: imagino al elector, ante la urna, dudando entre dos candidatos, como quien vacila un instante en la tienda antes de decidirse por una marca u otra de dentífrico... La que se haya grabado en su cerebro será la que decida su opción (Packard, 1965, p. 413). Se le acusó de vender al presidente como si fuera simple pasta de dientes. El candidato demócrata Stevenson se sintió incómodo con las estrategias publicitarias y la manipulación de los símbolos en la política: la sola idea de que vds. puedan tratar a los candidatos al más alto cargo de la nación como una marca de copos de avena... es la mayor indignidad a que podían llegar los procedimientos democráticos. Steveson, y sus escrúpulos, perdieron las elecciones.

A partir de aquella campaña comenzaron a plantearse dudas morales acerca del empleo de técnicas publicitarias en la política, pero ningu-

5 El más conocido, The man from Abilene (1952): http://www.youtube.com/watch?v=1rYk-1qlUR0 ó http://www.livingroomcandidate.org/commercials/1952/the-manfrom-abilene. na organización moderna -menos aún políticatiene presencia social al margen de los medios de comunicación... desde aquel momento la propaganda política dejó de consistir en la compra de espacios y pasó a significar la elaboración de anuncios televisados. Se convirtieron en publicidad, exactamente igual que los jabones, el café o la cerveza. El historial del candidato se convirtió en su imagen, su personalidad en un producto... (Clark, 1989, p. 394-395). Fueron los hombres de negocios quienes impusieron el estilo publicitario a la política americana.

\section{- 1960, Kennedy ante las cámaras}

La campaña presidencial de 1960 es la campaña que mejor refleja el poder de las imágenes sobre las palabras. Definitivamente deja de medirse al político por comparación con sus predecesores o sus contrarios para hacerlo por su comportamiento ante las cámaras, como si de una estrella se tratara. Y Kennedy será el primer presidente fruto de la televisión: acepta pasar por un entrenamiento para aprender a actuar ante las cámaras (Martín, 2002, p. 49). Un frío Nixon pierde en televisión frente a un carismático Kennedy.

McLuhan ve en JFK una imagen cercana a la del héroe -el tímido y joven sheriff- mientras la de Nixon, con sus mañosos circunloquios, sus ojos oscuros y la mirada fija, parece más el abogado de la compañia de ferrocarriles que suscribe contratos de expropiación contra los vecinos de una pequeña ciudad (McGinniss, 1972, p. 212). Nixon recorrió, a la antigua usanza, todos los estados de la unión pero lo que decidió las elecciones de 1960 fue la televisión. Todo hay que decirlo: la misma televisión que en 1968 le llevó a la presidencia con una campaña publicitaria que le despojó de la imagen de resentido y perdedor que arrastraba. 
Los debates en televisión -retransmitidos en directo por vez primera- eran la oportunidad para que los ciudadanos contrastasen la cualificación de los candidatos. Y, sin embargo, fue su apariencia la que primó sobre sus palabras. Quienes escucharon por radio a los candidatos, pensaron que Nixon era el más cualificado. Pero setenta millones de norteamericanos vieron por televisión el debate. Y la televisión cambió el rumbo de las cosas, como el propio JFK admitió (White, 1980, p. 353). Nixon, por su parte, se lamentó de prestar demasiada atención a lo que decía y demasiada poca a cómo aparecería (Nixon, 1962, p. 422).

\section{- Lyndon B. Johnson, Daisy spot}

Otro hito de la publicidad política -publicidad negativa- corresponde al partido demócrata durante la campaña presidencial de 1964, que enfrentó a Lyndon B. Johnson con Barry Goldwater. Los demócratas hicieron pasar a su oponente por un irresponsable, un ogro violento que haría estallar la guerra nuclear al mínimo pretexto... mientras Johnson es retratado como la paloma de la paz (Ogilvy, 1990, p. 211). El spot -el primer anuncio retirado de antena por ser excesivamente negativo: Daisy spot- es un logro de Bill Bernach: la asociación de la inocencia de una niña deshojando una margarita con la cuenta atrás del lanzamiento de un misil nuclear y su explosión ${ }^{6}$. Horrorizó a David Ogilvy, pero no tanto a quien será asesor publicitario de Margaret Thatcher, Tim Bell -de Saatchi \& Saatchi- que lo consideró un ejemplo de buena publicidad política (Eguizábal, 1998, p. 367).

6 http://www.youtube.com/watch?v=63h_v6uf0Ao. Otros spots, también realizados por Bernbach, como el que asociaba a Goldwater con el Ku Klux Klan, nunca llegaron a ser emitidos: http://www.youtube.com/watch?v=LWusOhZpq7w\&feature=related

\section{- Nixon: el amplio triunfo de la} televisión

Seguramente la campaña que consagró definitivamente el uso significativo del marketing aplicado a la política fue la que llevó a la presidencia de los EEUU a Richard Nixon. El republicano -que no sin resistencia se dejó fabricar una nueva imagen- fue empaquetado y vendido como si se tratara de un producto (McGinniss, 1972, p. 26). Nunca fueron tan patentes las analogías entre el marketing comercial y el político como en estos comienzos. Y esta analogía la han reforzado libros cuya tesis principal es que las campañas sirven para vender candidatos: McGinniss (1972), Rees (1992), Jamieson (1996).

El advenimiento de la televisión y el conocimiento de cómo podía emplearse para captar a los electores hizo desaparecer los viejos valores políticos: si la política y los principios carecían de utilidad a los fines electorales, el candidato de la televisión dejaba de regirse por las normas establecidas durante dos siglos de democracia y comenzaba a hacerlo por su desenvolvimiento ante las cámaras: si tartamudea, tiene tics, suscita risa o es capaz de emocionar. El estilo se transforma en la sustancia (McGinnis, 1972, p. 27 y ss.).

Nixon -áspero, distante- fracasó en 1960 por no contar con una prensa que mintiese por él y porque no supo cómo utilizar la televisión para mentir sobre sí mismo. Sencillamente: Nixon y Kennedy se reunieron cierto día en un estudio de televisión y cuando la luz roja de la cámara comenzó a lucir allí mismo se acabó Nixon. La televisión le hizo pagar el pato (McGinnis, 1972, p. 32).

La decisión de Nixon de usar la televisión en 1968 para ser presidente no fue fácil. Siquiera él creía en ello: Puede que al pueblo americano no le guste mi rostro, pero tendrán que escuchar lo que 
tengo que decir... (McGinnis, 1972, p. 190). Pero no era tan necesario cambiar el hombre como la impresión recibida: sin el nuevo medio, Nixon no tenía la menor oportunidad. Su equipo preparó programas en directo ${ }^{7}$ en los que un grupo representativo de ciudadanos -exquisitamente seleccionado- dirigía sus preguntas -temas cuidadosamente escogidos- al candidato ante el público -reclutado por la organización- en una cuidada escenografía y sin presencia de la prensa. El programa se realizaba en diferentes estados y las respuestas -apenas una docena- se ajustan a particularidades locales.

La evidencia de un importante desfase -manifestado a través de encuestas ciudadanas- entre la personalidad de los dos candidatos obligó a producir una serie de spots ${ }^{8}$ que acrecentaran la percepción de cercanía y entusiasmo de Nixon. Realizados por Eugene Jones, consistieron en sucesiones de diapositivas acompañadas por la voz de Nixon. Sus palabras, asociadas a las imágenes, le hicieron aparecer contemporáneo, imaginativo, involucrado, espontáneo, relajado (McGinnis, 1972, p. 91 y ss.).

El último día de la campaña, un anuncio con formato de artículo político de media página cuyo titular era Martes se publicó en el New York Times. Era un alegato escrito en defensa del voto a Nixon en contraposición a los otros dos candidatos. Vamos a votar por Nixon... convencidos de que no le aguarda a América un camino de rosas...

\footnotetext{
$7 \mathrm{http}: / /$ vimeo.com/4182735

8 Vietnam: http://www.youtube.com/watch?v=op5rTj8M7WM \&feature=related; Woman:

http://www.youtube.com/watch?v=KR-hEwgSkYk\&feature=related; Look at america:

http://www.youtube.com/watch?v=KR-hEwgSkYk\&feature=related; Youth

http://www.youtube.com/watch?v=wBIsxC77UG0\&feature=related; Reach out

http://www.youtube.com/watch?v=t| 7 Z2Se0091\&feature=related:
}

Y nadie le ayudará a vd. a tomar su decisión... Ahora le toca a $v$ d. decidir.

La victoria fue para Nixon. Aunque en opinión de algunos autores la campaña no sirvió de mucho y las razones de la victoria deberían buscarse en otra parte (Martín, 2002, p.25).

\section{- Saatchi para Thatcher: Iabour isn't working}

Margaret Thatcher estaba destinada a revolucionar la comunicación política de la derecha británica y buscó el modo de conectarla con sus potenciales votantes. La campaña - ejecutada por Saatchi \& Saatchi ${ }^{9}$ - siguió la línea de la publicidad política negativa de atacar al contrario y el uso de ataques devastadores contra el partido laborista. El mensaje central: labour isn't working - en el doble sentido de la frase: los laboristas no funcionan y el empleo no marcha- resumía el sentir de los ciudadanos y su principal preocupación: el desempleo. Mientras tanto, el partido de James Callaghan era reticente al empleo de la publicidad en política por tratarse de una herramienta demasiado vinculada al capitalismo.

Los políticos ingleses ya habían coqueteado con la publicidad antes de Saatchi $\&$ Saatchi. El primer intento de aplicar el marketing al estilo americano fue la campaña de los conservadores de 1970, basándose en el estilo Nixon 1968: una serie de spots para el candidato conservador Heath (Fallon, 1993, p. 203) marcaron un cambio en la promoción política en Televisión. Fueron emitidos en los espacios gratuitos concedidos por las cadenas de televisión a los partidos políticos. Pero el marketing político sólo llegaría de

9 http://www.youtube.com/watch?v=Jgupuhu_nfo 
mano de Saatchi \& Saatchi, cuya relación con los conservadores duró hasta $1987^{10}$.

La primera campaña de Saatchi para los tories fue en la primavera de 1978. Anunciada su emisión en prensa, mostraba imágenes en las que todo iba hacia atrás o funcionaba al revés, y terminaba con la frase en boca del político conservador Heseltine: hacia atrás o hacia adelante, porque ya no podemos seguir como hasta ahora. No se limite a esperar una vida mejor: vótela ya (Fallon, 1993, p. 208). Después llegarían los carteles: El laborismo no trabaja o jAlégrate! Los laboristas no van a durar toda la vida. En 1983 eslóganes como: Poner una cruz en la casilla de los laboristas es como firmar este documento..., el abajo firmante cede el derecho a elegir la escuela de sus hijos... Uno último comparaba el Manifiesto comunista con el programa laborista bajo la frase: Me gusta tu manifiesto, camarada, mostrándose a izquierda y derecha que eran idénticos (Eguizábal, 1998, p. 370-371).

\section{- Séguéla. La fuerza tranquila de un candidato radical}

En Francia, los socialistas utilizaron procedimientos hollywoodienses para que François Miterrand alcanzase la Presidencia de la República. Jacques Séguéla transformó al político en La fuerza tranquila -quizá antítesis de su realidad- y lo lanzó como si de una verdadera estrella de cine se tratara: su comunicación sería publicitaria, no política. Ninguna encuesta, ningún estudio determi-

10 Saatchi \& Saatchi ha vuelto a trabajar para los tories en las elecciones de 2010, que llevaron al poder a David Cameron. Y ha vuelto a hacerlo a través de la publicidad negativa, con mensajes como: He cogido miles de millones de las pensiones, vótame. O vota por el cambio. Vota Conservador; otros mensajes son: He doblado la deuda nacional; he doblado los impuestos de los pobres o He liberado antes de tiempo a 80.000 criminales. Oppenheimer, W. (2010, 4 de abril). Vuelven los Saatchi, vuelve la publicidad negativa. El País. P. 3 nará nunca el peso de aquella decisión... desde aquel día el socialismo al estilo francés iba a efectuar su entrada en la historia del mundo y nuestro star-system en el de la publicidad (Séguéla, 1982, p. 23). Frente al pragmatismo elemental de Giscard y Chirac, Mitterrand opondría su marca-persona. Una primera tentativa dentro del marketing político fue establecer el diagrama sociocultural de Francia situando en las cuadrículas de las expectativas las marcas presidenciales -los candidatos- en contienda, lo que reveló las fuerzas del candidato confrontadas a las debilidades de los adversarios. La ruta electoral quedaba trazada (Séguéla, 1982, p. 231): un encadenado de toda la campaña y un método. Definir la marca: un físico, un carácter y un estilo.

El maquillaje, pues, no se limitó al carácter del candidato. Antes y después -al estilo de las estrellas- ya se hizo adelgazar, se moduló su voz chillona o se arregló la dentadura a Thatcher, se pintarán canas a Felipe González o se calzarán alzas a Sarkozy. Nada descabellado hoy el planteamiento star system de Séguéla. La publicidad se dirigió a desactivar la percepción por la opinión pública de un Mitterrand propenso al extremismo político. La imagen y el slogan principal de campaña generaron un concepto político capaz de transformar positivamente todas las dudas de una sociedad que quería el cambio, pero sin sobresaltos. La Fuerza Tranquila ${ }^{11}$-el estilo- sintetiza este contexto en donde se sugiere el cambio sin sobresaltos. Mitterrand se plegó a los requerimientos visuales de Séguéla: visitó a su odontólogo y recortó sus colmillos -mejorando una imagen poco favorable para la televisión- y se utilizó una fotografía en el cartel donde se marcaba la calvicie que, en opinión del publicista, le

11 http://estrategica.com.co/blog/afiches/la-fuerza-tranquila/133.html 
daba un aire de abuelo que desarmaba la fama de radical que lo precedía.

\section{- Zapatero 2004: Zetapé}

Mientras el mundo transmuta en mundo anuncio (Eguizábal, 2009. P. 379), la política tiene cada vez más que ver con estrategias de representación, simulacro y seducción. En España el proceso de evolución de la comunicación política de propaganda a publicidad se produce durante la Transición -la excepcionalidad política lo difiere todo respecto de Europa y EEUU- y con una diferencia: lo que en los países de tradición democrática se produjo en décadas, en España tiene lugar casi de inmediato -apenas cinco años- e incorporando a las agencias publicitarias desde un principio.

El primer acto de comunicación política de la democracia -en realidad el último del franquismo- es el referéndum de la Ley de Reforma Política (1976) y ya contó con las agencias. Las elecciones generales de 1977 y 1979 fueron de ebullición política y de contenido político claro y definido en la comunicación. La propaganda política -en su sentido no peyorativo- está presente. Tal vez la primera gran operación de marketing sea la propia UCD: sin ideología clara o de centro, pero provenientes sus protagonistas del ejercicio político activo del franquismo. Las agencias no sabían aún nada de campañas políticas y se movían entre la intuición y el error, pero veían inevitable el empleo de las técnicas publicitarias.

En las campañas de los ochenta se producen novedades: algunos partidos se convierten ya en marcas y la imagen se muestra como herramienta para conseguir votos y conquistar el medio electoral (Eguizábal, 2009, p. 395). Julio Feo, uno de los pioneros de la comunicación política en
España y en parte responsable de la venta de Felipe González, ya dice en 1982 que vender un producto o una persona, a fin de cuentas, es lo mismo. Hay un mercado y un producto... (Barciela, 1983). En 1996 el PSOE se adentró en la estrategia agresiva estilo Saatchi (Eguizábal, 2009, p. 300) de la publicidad negativa con el vídeo: España en positivo ${ }^{12}$.

Las primeras elecciones del siglo XXI entran de pleno en el marketing: estilo seductor manejado por el candidato y su conversión -el político, ya no el partido- en marca. El cóctel de su candidatura -Tercera Vía de Blair, Nuevo Centro de Schröeder, Nueva Vía del PSOE y oposición tranquila- tiene sabor a ONG. La ideología está, definitivamente, muerta. Sólo se busca el posicionamiento en el mercado político: la política del siglo XXI es, más que nunca, la política del mercado (Laguna, 2010, p. 47). El concepto de ciudadano ha sido sustituido por el de consumidor (Hobsbawm, 2007, p. 109). Y esta vez se lograría con la marca ZP (Zetapé, acrónimo del lema Zapatero Presidente; el lema central de la campaña era Merecemos una España mejor), en la estela del mítico JFK del presidente Kennedy. Una marca de campaña con sesgo presidencialista. El propio candidato reflexionó al conocer la propuesta de DDB: ¿Lo va a entender la gente?, porque esto no se ha hecho nunca, ¿verdad? (Campmany, 2005, p. 237).

\section{- Obama 2008. Yes we can y la de- mocracia 2.0}

Un candidato de cuento de hadas, un liderazgo absolutamente carismático, el empleo de las tecnologías sociales basadas en Internet (web 2.0), el mensaje basado en el cambio y la esperanza

12 http://www.youtube.com/watch?v=vFVOqDSPB4o 
y la democracia líquida son los elementos del marketing político del siglo XXI. La política y los obstáculos (la condición social, racial, el nombre de resonancias musulmanas, el breve curriculum vitae del candidato...) no fueron inconveniente para confirmar sus propias palabras: Nunca fui el candidato más probable al cargo (Libert, Faulk, 2009. P. 3). Una de las claves para comprender la victoria electoral del Presidente Obama fue el experto dominio de las plataformas web 2.0 como Facebook, Twiter y Youtube -desde las primarias con Tú y yo conversamos-. El poder simbólico de la comunicación: Roosevelt desde la radio, Kennedy -y después Nixon- desde la televisión y Obama desde las redes sociales como el primer gobernante 2.0 de la historia (Laguna, 2010, p. 188): el marketing político organizado en red -la gran comunidad nacional de donantes, partidarios, voluntarios y personal de campaña (Libert, Faulk, 2009, p. 155)-donde los flujos de comunicación ya no son unidireccionales. Un nuevo estadio de la comunicación política.

\section{Conclusiones}

Las conclusiones que se extraen de nuestro estudio son:

- La comunicación política es un concepto abierto , y su definición varía dependiendo de cada autor y momento.

- La comunicación política es sinónimo de otras disciplinas afines como pueden ser la propaganda o la publicidad, utilizándose los términos de modo ambivalentemente y a veces de forma ambigua.

- Es una disciplina que desde sus orígenes está en constante evolución y seguirá, por su integración y utilización de las herra- mientas que aportan las Nuevas Tecnologías, evolucionando en los próximos años.

- Se puede afirmar que siguen vigentes términos aparentemente superados como Propaganda, aunque su uso sea minoritario por parte de algunos profesionales o estudiosos. Prueba de ello es que aún hoy algunos programas incluyen asignaturas o cursos con la denominación Propaganda o Propaganda Política y no con denominaciones más actuales.

- Tras el estudio de las campañas electorales más exitosas y relevantes del siglo XX - en Estados Unidos y Europa-, se observa desde mediado el siglo XX una rápida evolución de técnicas y medios y su asimilación por parte de la comunicación política para su posterior aplicación práctica.

- Podemos afirmar que, tras la progresiva permeabilización de la publicidad comercial por parte de la publicidad política - una vez que queda atrás la propaganda-, la tendencia general ha sido su transformación en comunicación política, entendiéndose ésta en un primer momento como una parte del marketing-mix y, posteriormente, como elemento estratégico del mismo, concluyendo que la comunicación política se integra como un elemento primordial del marketing político, y éste como elemento crucial en las estrategias de posicionamiento de los partidos en sus comunicaciones con los electores. Las estrategias de comunicación política quedan subordinadas a las estrategias de marketing político.

El marketing político se convierte así en un conjunto de estrategias -comunicativas y de otra índole- programadas, diseñadas y ejecuta- 
das durante el período electoral, post-electoral e intra-electoral, de modo que instrumentali- cen los valores, creencias y actitudes del electorado, real y potencial, en todo momento.

\section{Bibliografía}

Alan Nelson, R. (1996). A Chronology and Glossary of Propaganda in the United States. Westport, Connecticut: Greenwood Press.

ANEI (s.a.) Publicidad Institucional. Consultado el 10/01/2011 en: http://www.a-nei.org/descargas/task,doc_view/gid,103/ Barciela, F. (1983, 16 de enero). Cómo se fabrica un presidente. ABC. Madrid.

Barnés, J. S. (2007) El candidato ante los medios: telegenia e imagen política. Madrid, Fragua.

Barroso Saiz, FJ. (2010). Marketing político y electoral. Madrid: Pirámide

Benito, A. (1976) Prólogo. En MASSÓ, R. y NEBOT, J.E. Introducción al "Politing": lanzamiento de un aspirante. Barcelona: Interalas.

Browne, M. y Fitz Patrick, M. (2004). Manual de los medios de comunicación social en períodos electorales. Buenos Aires: La Crujía.

Canel, M.J. (2005). Comunicación política: técnicas y estrategias para la sociedad de la información. Madrid: Tecnos.

Canel, M.J. (2006). Comunicación política: una guía para su estudio y su práctica. Madrid: Tecnos.

Capmany, J. (2005). El efecto ZP: 1000 días de campaña para llegar a La Moncloa. Barcelona: Planeta.

Caro Almela, A. (2007). Fundamentos epistemológicos y metodológicos para un estudio científico de la Publicidad. Pensar la publicidad. Revista Internacional de Investigaciones Publicitarias, 1(1), 55-82.

Caro Almela, A. (2008) De la propaganda a la publicidad. Pensar la Publicidad. Revista Internacional de Investigaciones Publicitarias. 2 (1), 9-12.

Castillo Sánchez, G. (1988). Propaganda y publicidad política. Comunicación y medios. 7-8, 41-46.

Clark, E. (1989). La publicidad y su poder. Barcelona: Planeta
Del Rey Morató, J. (1989). La comunicación politica. Madrid: Eudema Universidad

Delgado, C.; Derecho, E. (2000). Variables relacionadas con la percepción de publicidad electoral. Psicología política. $21,31-54$

Diccionario de la Fundación Ciudad Política (2004, 21 de abril). Publicidad politica. Consultado el 31/01/2011 en: http://www.ciudadpolitica.com/modules/wordbook/entry. php?entryID=28

Eguizábal Maza, R. (1998) Historia de la publicidad. Madrid: Eresma \& Celeste.

Eguizábal Maza, R. (2009) Industrias de la conciencia: una historia social de la publicidad en España. Barcelona: Península. El Mundo (2011, 24 de enero). La música suena bien, ahora hay que ponerle letra. El Mundo, p. 3.

El País (2010, 20 de octubre). Zapatero justifica los cambios para "fortalecer el Gobierno" y "explicarse mejor". El País. Consultado el 31/01/2011 en: http://www.elpais.com/articulo/espana/Zapatero/justifica/cambios/fortalecer/Gobierno/ explicarse/mejor/elpepuesp/20101020elpepunac_25/Tes

Ellul, J. (1965). Propaganda: the formation of men's attitudes. New York: Vintage books

Fallon, I. (1995). Saatchi E Saatchi: la publicidad al poder. Barcelona: Planeta de Agostini.

Ferry, J.-M.; Wolton, D. et al. (1995). El nuevo espacio público. ( $2^{\mathrm{a}}$ ed.). Barcelona: Gedisa.

Hobsbawm, E. (2007). Guerra y paz en el siglo XXI. Barcelona: Crítica.

Huici Módenes, A. (1994). Propaganda y publicidad política: algunas cuestiones terminológicas. Questiones publicitarias. Revista de métodos, análisis y estrategias de la comunicación publicitaria. 3, 96-104

Jamieson, K.H. (1996). Packaging the presidency. New York, Oxford: Oxford University Press. 
Laguna, A. (2010). Las claves del éxito político. Barcelona: Península.

Libert, B.; Faulk, R. (2009) Obama, Inc.: el éxito de una campaña de marketing. Madrid: Pearson education.

Maarek, Ph. J. (1997). Marketing politico y comunicación: claves para una buena información política. Barcelona: Paidós.

Marcos, I. de (2008). Publicidad electoral: 2008, punto de inflexión. Anuncios. 1228, 22-23.

Martín Salgado, L. (2002). Marketing político: arte y ciencia de la persuasión en democracia. Barcelona: Paidós, 2002.

Mayer, M. (1965). Política y publicidad. En Sandage, C.H.; Fryburger, V. El impacto publicitario. Barcelona: Editorial Hispano Europea

Méndiz Noguero, A. (2007) Diferencias conceptuales entre publicidad y propaganda: una aproximación etimológica. Questiones publicitarias. Revista de métodos, análisis y estrategias de la comunicación publicitaria. 1(12), 43-61.

Mori Luca, Ph.D. (2010). Consensus and democratic legitimacy: political marketing versus political philosophy. Hamburg Review of Social Sciences. 5 (1), p. 62-86.

Nimo, D. y Sanders, K. (1981). Handbook of Political Communication. London: Sage.

Nixon, R.M. (1962). Six crises. Garden City: Doubleday Ogilvy, D. (1990) Ogilvy y la publicidad. Barcelona: Folio. Oppenheimer, W. (2010, 22 de enero). Cameron sufre un descalabro con la dimisión de su ideólogo mediático.
El País. Consultado el 31/01/2011 en: http://www.elpais. com/articulo/internacional/Cameron/sufre/descalabro/dimision/ideologo/mediatico/elpepiint/20110122elpepiint_2/Tes Packard, V. (1965). El creciente poder de la publicidad. En Sandage, C.H.; Fryburger, V. El impacto publicitario. Barcelona: Editorial Hispano Europea

Pérez García, D. (2003). Técnicas de comunicación política: el lenguaje de los partidos. Madrid: Tecnos.

Pineda Cachero, A. (2007). Propaganda y publicidad comercial. Questiones publicitarias. Revista de métodos, análisis y estrategias de la comunicación publicitaria 1(12), 107-128.

Pizarroso Quintero, A. (1999) La historia de la propaganda: una aproximación metodológica. Historia y Comunicación Social 4, 145-171.

Rusiñol, P. (2011, 31/01). Aguirre lanza ocho campañas de publicidad antes del 22-M. Público. Consultado el 31/01/2011 en: http://www.publico.es/espana/358983/aguirre-lanza-ocho -campanas-de-publicidad-antes-del-22-m

Salmon, Ch. (2007) Storytelling: la máquina de fabricar historias y formatear mentes. Barcelona: Península.

Schramm, W. (1965). Efectos de la comunicación masiva. En Sandage, C.H.; Fryburger, V. El impacto publicitario. Barcelona: Editorial Hispano Europea

Séguéla, J. (1982) Hollywood lava más blanco. Barcelona: Barcelona Business Books.

White, T. H. (1980). The making of the president, 1960. New York: Atheneum. 